\title{
Canary in the coalmine: Norwegian attitudes towards climate change and extreme long-haul air travel to Aotearoa/New Zealand
}

\author{
James E.S. Higham ${ }^{\text {a }}$ and Scott Allen Cohen ${ }^{\text {ab }}$ \\ a Department of Tourism, School of Business, University of Otago, PO Box 56, \\ Dunedin, New Zealand. Email: james.higham@otago.ac.nz \\ ${ }^{\mathrm{b}}$ School of Tourism, Bournemouth University, Dorset House, Talbot Campus, \\ Poole, Dorset, BH12 5BB, UK. Email: scohen@bournemouth.ac.uk
}

\begin{abstract}
Accelerating global climate change poses considerable challenges to all societies and economies. The European Union now targets a $20 \%$ reduction in $\mathrm{CO}_{2}$ emissions by 2020 . Indeed, the Labour-led Norwegian government is committed to carbon neutrality across all sectors of the economy by 2030. Aviation has been identified as a rapidly growing contributor to $\mathrm{CO}_{2}$ emissions. This article reports on a research project that explored Norwegian attitudes towards climate change, particularly as they relate to extreme long-haul air travel to Aotearoa/New Zealand. It reveals that the 'dream trip' to New Zealand for Norwegians is still largely intact. It also finds evidence of 'air travel with a carbon conscience' arising from growing concern for high frequency discretionary air travel. Evidence of denial of the climate impact of air travel that recent studies have revealed was largely absent. Interviewees expressed a greater concern for short-haul air travel emissions than for the climate impact of long-haul travel. However, intentions to adapt long-haul travel behaviours were expressed, highlighting the need to monitor consumer attitudes towards the impact of air travel on climate change. We conclude that Norway is a vanguard European tourism market in terms of climate sensitivity.
\end{abstract}

Keywords: Climate change, aviation, $\mathrm{CO}_{2}$ emissions, extreme long-haul travel, Norway, New Zealand. 


\section{Introduction}

Accelerating global climate change and heightened sensitivity to human-induced causes of climate change pose considerable challenges to all societies and economies (Smith \& Rodger, 2009). It is widely acknowledged that the tourism industry is implicated in climate change in terms of both cause (Becken, 2002; Gössling \& Hall, 2005; Becken \& Hay, 2007) and effect (e.g., Wall \& Badke, 1994). An expanding body of academic literature addresses the impact of aviation on climate change (Becken, 2007; Gössling \& Upham, 2009; Hares, Dickinson \& Wilkes, 2010). It is now accepted that a single long-haul return flight accounts for a high proportion of an individual's total annual per capita emission levels (Gössling, Haglund, Kallgren, Revahl \& Hultman, 2009). Discourse concerning the reduction of $\mathrm{CO}_{2}$ emissions is considerable in Europe. The European Union has targeted a $20 \%$ reduction in $\mathrm{CO}_{2}$ by 2020 (Gössling \& Hall, 2008). Such targets raise important questions concerning the sustainability of European long-haul visitor markets.

Aotearoa/New Zealand is a geographically isolated island nation in the South Pacific Ocean. Inbound tourism is a cornerstone of the New Zealand economy. It numbered 2.46 million visitors in 2008, representing \$9b in direct foreign exchange earnings, 9.2\% of GDP and employment of 181000 FTE (Ministry of Tourism, 2009a). Eastern seaboard Australia apart, the majority of all inbound arrivals to New Zealand are longhaul travellers. New Zealand's global marketing brand, '100\% Pure New Zealand', has come under increasing scrutiny as a result of the energy intensive nature of the industry (Becken, 2007), most particularly the $\mathrm{CO}_{2}$ emissions associated with simply travelling to and from New Zealand (Smith \& Rodger, 2009). Indeed, the Ministry of Tourism (2009b: np) observes that "New Zealand's distance from most key markets makes journey-related greenhouse gas emissions, costs and consumer perceptions key issues for the sector".

Norwegian nationals have been described as hyper-mobile (Høyer, 2000). In 2008 Norwegians undertook 22.1 million trips (compared with 17.3 million in 2006) of at least one night duration, of which $34 \%$ were outbound (Statistics Norway, 2010). The most popular destinations abroad in 2008 were Denmark, Sweden and Spain. The Ministry of Tourism (New Zealand) (2010) international visitor arrivals (IVA) data record 29242 inbound arrivals from Northern Europe (Norway, Sweden and Finland) in the year to January 2010. While the Norwegian inbound tourism market to New Zealand is modest ( $0.7 \%$ of total international arrivals to New Zealand in 2009), our interest in the Norwegian market arises from the commitment of its recently re-elected Labour-led government (September 2009) to become carbon neutral across all sectors of its economy by 2030 (Gössling, 2009). Norway currently boasts one of the OECD's highest levels of carbon taxation to mitigate global warming (OECD, 2009). This national policy position is indicative of "an outspoken focus on carbon neutrality... influenced by national debates on climate change" (Gössling, 2009:29). As such, Norwegian attitudes towards carbon neutrality may indicate a wider groundswell of climate concern in European markets (Gössling, 2009). Within this context, this article 
presents an in depth exploration of Norwegian attitudes towards climate change, specifically as it relates to extreme long-haul travel to New Zealand.

\section{Carbon, air travel and extreme long-haul tourism to New Zealand}

Tourism is an energy intensive industry (Becken, 2007) that is estimated to contribute $5 \%$ of total global $\mathrm{CO}_{2}$ emissions (Gössling, 2002). Of this contribution to $\mathrm{CO}_{2}$ emissions, Gössling (2002) attributes upward of $90 \%$ to transport. As international tourist arrivals approach one billion tourists per annum, the UNWTO (2008) forecasts 1.6 billion international tourists in 2020. Calls for the tourism industry to 'move onto a sustainable emissions path' (Becken, 2007; Hares et al., 2010) are increasing. Quite how this will be achieved, particularly as it relates to extreme long-haul air travel, is an open question.

While international air transport emissions have not been subject to liability under the Kyoto Protocol, "pressure is mounting globally for international aviation to be included in post-Kyoto arrangements" (Smith \& Rodger, 2009: 3438). In the current absence of an international policy position on responsibility for international aviation emissions, countries such as New Zealand have started to consider "whether destination or source countries should be viewed as ethically responsible for the greenhouse gas emissions attributable to visitors" (Smith \& Rodger, 2009: 3438). Awareness of the phenomenon of climate change is high in Europe, although a 'psychology of denial' has, and continues to surround air travel (Gössling \& Peeters, 2007). Uncertainty of relative transport choice efficiencies, elevation of the social and economic importance of air travel, and confidence in technical solutions are reasons that have been put forward to explain prevailing attitudes and continuing high demand for air travel (Gössling \& Peeters, 2007; Hares et al., 2010).

The relationship between tourism and climate concern is now the subject of increasing academic attention. Gössling and Hall (2006) identify two branches of research that address this field. The first recognises that much tourism is dependant on climate, and that climate change will be associated with a range of consequences for tourism destinations (Agnew \& Viner, 2001; de Freitas, 2005). The consequences may be particularly acute for nature-based tourism resources (Richardson \& Loomis, 2005) and for specific tourist activities (Scott, Wall \& McBoyle, 2005). The second focuses on the sensitivities of tourists themselves (de Freitas, 2005), as manifest in changes in attitude and behaviour in response to climate concerns. Such changes may include choice of destination and timing of visits, perhaps extending to the abandonment of some destinations, and the discontinuation of some forms of tourism.

Gössling and Hall (2006) warn against assumed linearity between climate change perceptions and travel behaviour. Indeed Hares et al. (2010: 466) note, in reference to the United Kingdom, that while considerable effort has been invested in communicating to the public the need to reduce the carbon footprint of day-to-day domestic living, "one area where emissions are growing rapidly, and little attempt has been made to increase consumer understanding of the impacts on climate change is 
holidays, particularly those involving air travel". Hares et al. (2010) conclude that climate concerns are either disregarded or suppressed when planning holidays, a point that echoes the earlier findings of Becken (2007). Hares et al. (2010: 472) also report on the high value associated with holidays, to the point that few are "...prepared to accept personal responsibility for the impacts their holidays have on climate change, [but rather] put forward a number of denial mechanisms for why responsibility lies with governments, businesses and other countries, rather than with the individual".

The relationship between climate change and attitudes towards long-haul air travel is yet to receive dedicated attention. Smith and Rodger (2009) report the increasing media attention being paid in Europe to the contribution of long-haul travel to climate change. Following the UK Department of Environment, Food and Rural Affairs (DEFRA), Smith and Rodger (2009) define air travel over distances greater than $3700 \mathrm{~km}$ from origin airport as long-haul. They note that "for the case of international travel to New Zealand, all origin airports meet the distance requirements for long-haul, with the exception of some Australian (e.g., Sydney) and Pacific Island (e.g., Nadi, Fiji) origin airports, which are medium-haul $(425-3700 \mathrm{~km})$ under the DEFRA approach" (Smith \& Rodger, 2009: 3441). Under this approach, it is perhaps more accurate to define European travel to New Zealand as 'extreme long-haul' or 'multiple long-haul', given the necessity of two flights in excess of $3700 \mathrm{~km}$ as a minimum of air travel to reach the destination.

The $\mathrm{CO}_{2}$ emissions attributed to New Zealand's inbound tourism markets are inescapably linked to visitor origin. European markets consume more energy than other New Zealand inbound visitor markets due to sheer distances travelled (Becken, 2002). Indeed, one return journey from Europe to New Zealand by a single traveller equates to almost half of the average total per capita domestic $\mathrm{CO}_{2}$ emissions of a European citizen. This estimation is based on 4.2 tonnes of $\mathrm{CO}_{2}$ emitted (per passenger) in return air travel (Smith \& Rodger, 2009) and Monbiot's (2007) approximation that an average UK citizen emits 9.5 tonnes of $\mathrm{CO}_{2}$ a year. This figure does not account for the established fact that the effects of aviation emissions on climate are significantly greater than $\mathrm{CO}_{2}$ emissions alone (Penner, Lister, Griggs, Dokken, \& McFarland, 1999), which may be accommodated with the use of Brand and Boardman's (2008) aviation impact multiplier range of 1.5 to 4.0. Furthermore, 4.2 tonnes of $\mathrm{CO}_{2}$ exceeds by $20 \%$ the sustainable emissions path of 3.5 tonnes of $\mathrm{CO}_{2}$ emitted globally per person per year as calculated by Gössling et al. (2009).

In contrast to visitors from Australia (who represent $37 \%$ of all international visitors to New Zealand, and $13 \%$ of $\mathrm{CO}_{2}$ emissions), European visitors comprise $18 \%$ of total visitor numbers yet account for $43 \%$ of the emissions associated with international visitor air travel (Smith \& Rodger, 2009). All of New Zealand's long-haul markets have declined over the last twelve months; Asia (-16\%), Americas (-12\%) and Europe $(-9 \%)$. By contrast, New Zealand's two medium-haul markets have increased over the same time period; Australia (+7\%) and the Pacific Islands (+13\%) (Ministry of Tourism, 2009c). These market trends are attributed by the Ministry of Tourism 
(2009c) to the global economic recession, yet the relevance of climate concerns to such trends remains unknown.

Despite rhetoric linking air travel and climate change (Becken \& Hay, 2007), remarkably little academic attention has been paid to understanding tourist awareness, changing attitudes and travel behaviours as they relate to climate concern (Hares et al., 2010). However, a few academic studies, and one government report (Donnelly, 2008), have emerged that address such timely questions as tourist awareness (Gössling, Bredberg, Randow, Sandström, \& Svensson, 2006) and perceptions of climate change (Becken, 2004; Hares et al., 2010; Shaw \& Thomas, 2006), attitudes to climate mitigation measures (Becken, 2007) and responses to carbon offsetting programmes (Gössling et al. 2009).

These studies have generally established the fact that awareness (Becken, 2004) and understanding (Gössling \& Peeters, 2007) of tourism's contribution to climate change are low, as are concerns about the impacts on climate associated with holiday air travel (Gössling et al., 2006; Shaw \& Thomas, 2006). More recent studies suggest increasing awareness of and concern for air travel's $\mathrm{CO}_{2}$ emissions (Gössling, Peeters \& Scott, 2008), although such findings vary significantly both between and within discrete markets (Donnelly, 2008; Gössling et al., 2009). While little evidence currently exists to suggest a voluntary reduction in air travel behaviour (Becken, 2007; Donnelly, 2008; Hares et al., 2010), some studies indicate growing awareness and reluctant acceptance of the need for current high frequency air travel behaviours to become more restrained (Shaw \& Thomas, 2006).

Our focus on Norwegian climate concerns and travel behaviours, then, arises from:

1. The established hyper-mobility of Norwegian nationals, and continuing growth in Norwegian mobilities (Høyer, 2000);

2. The Labour-led Norwegian government's commitment to become carbon neutral across all sectors of its economy by 2030 (Gössling, 2009);

3. The growing prominence of climate change as a subject of national debate in Norwegian media (Gössling, 2009), raising the possibility that within the European climate change context, Norway may be an indicator long-haul travel market, and;

4. The importance of consumer climate concerns and changing travel behaviours to extreme long-haul destinations such as New Zealand (Ministry of Tourism, 2009a).

\section{Method}

The empirical work presented here is part of a broader study on climate change concern and attitudes to air travel in New Zealand's long-haul European markets. This study required return air travel from New Zealand to key European study sites. In respect to the growing tradition of mitigating researcher impacts (see Lusseau \& Higham, 2004), we chose to voluntarily offset the aggregated air travel $\mathrm{CO}_{2}$ emissions arising from the research using a New Zealand-based carbon sequestration scheme. This action reflects the shared position of the researchers, that aviation carbon 
emissions are a significant cause of climate change that should be minimised and/or mitigated. However, the research approach was non-activist and as such sought to elicit subjective personal perspectives on the research questions.

For the purposes of this study the authors adopted an interpretive research paradigm, and conducted the empirical research within a relativist ontology (Denzin \& Lincoln, 2005). Qualitative materials were collected via a programme of interviews conducted in Norway in June 2009, during a period when one of the co-researchers held the position of visiting researcher at the University of Stavanger. The interview programme sought to address participant opinions on climate change, and then engage participants in an in-depth discussion of climate change concerns as they relate to three key themes; 1. Day-to-day domestic living decisions and behaviours, 2. Air travel decision-making (domestic and international) and, 3. Attitudes towards long-haul air travel to New Zealand (Table 1). The relevance of the current global economic downturn as a related factor in travel decision-making processes was accommodated as a central element of the empirical research project.

\section{Insert Table 1 here}

Interview participants were recruited in Stavanger (Norway) employing a snowball sampling technique. Selection criteria required that interview participants self-identify as Norwegian nationals (minimum age of 18 years) and were willing to be interviewed face-to-face in English. A total of fifteen semi-structured open-ended interviews, ranging from 30-60 minutes, were conducted at neutral sites and digitally recorded. The interview programme achieved a series of in depth and complex one-to-one human interactions (Fontana \& Frey, 2005), producing rich volumes of qualitative material that showed evidence of saturation in the latter part of the interview programme. The interview participants included eight females and seven males with ages that ranged from 27-67 years (Table 2). Interviewees were highly educated, and included seven industry professionals, three postgraduate students, two university academics, two university administrators and one retiree. The profile of study participants reflects the generally well educated and affluent large upper middle class

and flat income distribution in Norway (OECD, 2009). However our programme of in depth interviews cannot be considered to represent Norwegian society as a whole.

Reflecting Høyer's (2000) study of Norwegian hyper-mobility, the travel profiles of the study participants described a highly mobile group of individuals (Table 3 ). This included domestic Norwegian and wider European travel, for both personal and professional reasons. Multiple monthly flights were not uncommon. Regular domestic flights to meet business commitments and/or to see family were seen as a consequence of the physical geography of Norway, and the lack of alternative efficient transport options. Reduced business travel following the 2008 global financial crisis, and the uptake of computer-mediated solutions as a substitute for high levels of business travel, were considered an important part of the move to a sustainable emissions path. Most, however, also expressed the common need for Norwegians to take regular holidays in warm destinations. Regular flights in Europe were the norm, reflecting the propensity of Europe's hyper-mobile to take multiple short-break holidays each year (Høyer, 2000, Hares et al., 2010). 


\section{Insert Tables 2 and 3 here}

Following transcription, the empirical material was interpreted independently by the researchers using an inductive thematic analysis approach (Patton, 2002), which involved reducing the empirical material into categories guided by the interviewees' narratives and the research aims (O'Reilly, 2005). Emergent themes were highlighted through this immersive double-blind process to identify both consistency and divergence between interview transcriptions. After triangulating the respective individual interpretations of the co-researchers, further joint discussions facilitated the refinement of the interpretations that follow.

\section{Attitudes towards climate change and air travel}

At the most general level, and in contrast to several existing studies (Becken, 2004; Gössling \& Peeters, 2007; Hares et al., 2010) this study found evidence of widely held climate change concerns, and acknowledgement of the significance of human contributions to climate change. There was an expressed view that climate change discourse in Norway has moved from debate to acceptance of, and response to, the issue of global climate change. Acceptance of climate change, and the reality that climate change poses a significant and unavoidable problem, was forthright.

Yes, I mean the evidence is so obvious now from different sources so that I'm really convinced. And I think it's quite obvious that there is a direct link between human activities and climate change. I see it as a problem (Johannes, 57).

This acceptance extended to the opinion that climate concern is no longer isolated in Norwegian society. 'It's quite mainstream in Norway that the human contribution is probably the major cause of climate change... [and] it's my responsibility to do something about it' (Svein, 35). This study found consistent evidence of efforts in daily domestic life to mitigate individual contributions to climate change. Reduced car use, interest in the next generation of electrical cars, and the preferred purchase of local foods are actions that were motivated in part by climate change.

We have two cars but we use them perhaps one third now as we did a year ago. We're waiting for the next generation of electric cars with five seats and decent driving range, that's the next step... It's motivated by climate change (Svein, $35)$.

However, a sense of insignificance in terms of domestic responses to global climate change was also evident, to the point in some cases of deliberate neglect of climate change as a matter of daily concern. In other cases, climate change was seen as part of the justification for changing domestic behaviours, but in terms that were secondary to such things as saving money (reduced energy consumption) and being physically active (e.g. riding a bicycle rather than driving to work). 'Climate is not the reason 
why I walk, I walk because I want to get some exercise and fresh air... [perhaps] it's both economic and climate. A combination...' (Anette, 35). A common voice expressed the need for daily climate action to be both convenient and cost effective. Until such time climate concern will remain a justification for some existing daily behaviours that are otherwise seen to be largely insignificant in addressing the climate change challenge.

\subsection{Attitudes to travel}

The importance that mobile people ascribe to travel is well established (Becken, 2007) and described in relation to the difficulty of changing established patterns of behaviour (Gossling, 2009; Randles \& Mander, 2009). This study found a love of travel among participants. Deeply entrenched travel behaviours, and a profound reluctance to compromise an established 'appetite' for holidays were clearly evident. The importance of travel vis-à-vis broadening horizons, the upbringing of children, and more broadly in terms of personal identity and lifestyle, were clearly articulated. 'We have travelled quite a lot as part of bringing up our kids. So concerning the climate, we haven't taken that into our interest of travelling and seeing other places' (Silje, 45).

We found little to suggest the individual curtailment of travel ambitions, either currently or in the immediate future. Rather, the view was expressed that other aspects of life in Norway would be sacrificed before the luxury of travel.

I'm not going to stop travelling but if we had to I would save in on other things before I saved in on my travels. If we came to the point where you had your own quotas, I'd rather save them for my travelling (Grethe, 27).

The Norwegian appetite for seasonal holidays in warm climates was most evident. 'For myself... if I have the money and time to do it I wouldn't be too worried about producing more $\mathrm{C}_{2} \ldots$ It is important for me to get to the sun and to relaxing places' (Rita, 34).

Beyond the denial strategies identified in the UK by Donnelly (2008) and Hares et al. (2010), we found in Norway sentiments of guilt associated with travel. 'I know it is problematic and I should be concerned more, but my conscience is not bad because of taking flights at all' (Rita, 34). While an awareness of the impacts of air travel on climate change was demonstrated, concerns arising from this awareness are, it seems, still able to be suppressed.

...Of course it frightens me to hear it, because if I do it everyone else can too! I know it matters.... But maybe I am not responsible enough. I think that in many ways I am a typical Norwegian in this way of thinking (Silje, 45).

Our qualitative material provided evidence not of denial, but rather of acceptance, and concern arising from both a sense of insignificance vis-à-vis domestic responses to climate change, and reluctance to curtail air travel behaviours. 


\subsection{Attitudes towards long-haul air travel to New Zealand}

Not one study participant indicated that climate change would deter consideration of extreme long-haul air travel to New Zealand. Rather, visiting New Zealand was most commonly described as an extraordinary or 'once in a lifetime' opportunity. In this respect, an extreme long-haul trip to New Zealand was seen to be justifiably set apart from concerns arising from regular air travel. The 'dream trip' to New Zealand was, for the majority, intact, and disassociated from domestic concerns arising from climate change. 'To fly to New Zealand is not an everyday thing... Since I am not flying to New Zealand every week the carbon will not affect me at all' (Frode, 37).

For the time being, New Zealand is viewed in Norway as an extraordinary travel opportunity to an extent that overrides climate concerns. 'I would think about it [the emissions] but I would still do it. ... I'm not going to stop travelling even though I think about the impact that I have' (Grethe, 27). However, we found evidence to suggest that the Norwegian long-haul market has in recent years become increasingly sensitive to a growing social stigma associated with air travel. Although long-haul air travel has in the past been perceived as a status symbol, it is increasingly viewed with social disapproval. 'Ten years ago it would be a status thing to go somewhere very far and stay there for a couple days and come back again and today it's the opposite' (Pål, 34). This view did not extend to discontinuation of long-haul air travel, but was clearly associated with expressions of concern arising from long-haul air travel of relatively short duration.

The safeguarding of long-haul air travel intentions is in part explained by the relatively long planning horizons and anticipation phase associated with such trips. In this respect, evidence of a more critical appraisal of regular short-haul air travel, which was seen to be more self-indulgent and flippant in relative terms, was apparent.

I think for the ordinary people if they decide to go on a trip like that [to New Zealand], they will plan it for so long and when they have made their decision, they will do it. So I don't think that thinking about carbon will make any difference but perhaps short-haul travelling will be more affected (Ida, 52).

Our interpretations of the empirical materials coalesced around evidence of an increasing social conscience surrounding long-haul air travel to New Zealand. What we describe as 'air travel with a carbon conscience' is evident in sentiments that indicate changes in existing travel behaviours, most notably the appropriate duration of visits to extreme long-haul destinations such as New Zealand. Many expressed the view that if ticket prices increase (perhaps in association with $\mathrm{CO}_{2}$ taxation measures) increased length of stay would be an immediate consequence, which in turn would mitigate sentiments of carbon guilt associated with long-haul air travel. 'You don't feel so guilty if you stay longer. You feel more guilty if you are a regular traveller, or going every week on business travel' (Tone, 58). This view was widely expressed, despite the fact that length of stay is in fact irrelevant in terms of the actual $\mathrm{CO}_{2}$ emissions arising from the use of air transportation. 
A second and closely related manifestation of 'air travel with a carbon conscience' arises from the intention to combine multiple destinations and multiple motivations of visit in a single long-haul journey. Visiting New Zealand was in some cases justified only in association with a visit to Australia. 'I think that if I was to go there, it is not New Zealand, it is New Zealand and Australia. I won't travel that far without going to Australia' (Bjørn, 41). Additionally, for some, air travel to New Zealand could only be justified by having multiple reasons for travel rather than discretionary leisure travel alone. 'I think I would be much less inclined to go there due to climate change for pleasure or for vacation. But if I had to go there for some reason for work, it [climate change] would mean much less' (Lars, 53). Indeed some, such as Bjørn, anticipated changes in the nature of New Zealand visitor experiences in association with longer duration visits.

I am not against travelling, but I rather try to travel for a long time; go away for a few months and experience the culture and live for a while... then I get to interact and get to know the people on another level.

A third and related element of 'air travel with a carbon conscience' is associated with unsustainable frequent short-haul air travel. While our focus was directed at attitudes towards extreme long-haul air travel, a greater concern for short-haul travel was widely expressed. In this respect, the clear association between short-haul air travel and climate change was considered inexcusable. 'I think the mass use of airplanes as it is today is a huge polluter. I don't think we can afford to have that short-distance, short-time travel to other places' (Lars, 53). The disengagement of actual monetary travel cost from the wider costs of short-haul air travel was also viewed with concern.

Okay, it's great going to London for a weekend and going to Paris for a weekend, it's not too far, it's relatively cheap. But still, it's the issue that we can't do it - I don't think that everyone can do that all the time. Not in the long run. It's going to be too much (Grethe, 27).

\subsection{Clear the confusion}

Awareness of and high concern for the relationship between air travel and climate change was clearly expressed by interviewees, and this represents a divergence from recent studies (Becken, 2007; Gössling et al., 2006; Shaw \& Thomas, 2006). Nonetheless, for some there remains a general lack of willingness to significantly reduce their frequency of individual air travel. This partly arises from an inability of air travellers to adequately recognise or understand their individual contribution to human-induced climate change.

Actually, I do not feel it. And in a way it's not logical... This problem is of such a complex nature that I feel... my effect is so limited that it must be measured to other types of problems in the world... Even though I know it's a problem, it becomes a very small problem for me (Johannes, 57). 
While awareness of the impact of air travel on climate change exists in Norway, it seems that one of the biggest factors preventing individuals from reducing their flying behaviours is the prevailing view that the effects of air travel on climate change are vague and abstract. The actual effects of air travel have not been clearly communicated or understood. Consequently, while daily behaviours may be changing to an extent, air travel behaviours remain largely entrenched. Some recognised a responsibility for international carriers themselves to move beyond token environmental practices in an unequivocally unsustainable transport sector. 'The air companies, I think they should try to make us more aware... because I don't know how much... one flight would pollute the environment' (Grete, 27). The need for an honest appraisal of the climate change consequences of air travel decisions was clearly in evidence.

When drawn into a discussion of the impacts of air travel, many found the reality of air travel impacts disconcerting. Some suggested that greater clarity around the carbon footprint of a long-haul trip may trigger a different response from the travelling public. 'Maybe if people knew how much the emissions are, going to New Zealand for instance, I think maybe that would help' (Anette, 35). The need for the current confusion to be addressed extends to carbon offsetting initiatives. 'You don't really know where the money goes, like, what are they being used to do? ... People don't really know' (Grethe, 27). This lack of clarity poses a significant barrier to the adoption of voluntary carbon offsetting.

This research indicates that individual $\mathrm{CO}_{2}$ quotas and voluntary carbon offsetting are widely perceived to be too abstract. Unless made to be mandatory, carbon offsetting is considered by many to be a matter only of paying to offset personal guilt. 'So I pay my tax when I go. What does that cover? 'My bad conscience for going by plane' (Hilda, 67). A paradox emerges in that individuals are prepared to an extent to modify their daily behaviours, but not compromise their appetite for air travel. There is evidence of an attitude-behaviour gap in which individuals are aware of the impacts of aviation on climate and feel the problem should be addressed, but are not assuming individual responsibility by reducing air travel frequency. This disjuncture reflects recent work in the field of air travel (Hares et al., 2010; Randles \& Mander, 2009) that highlights the weak relationship between personal values and attitudes (e.g., concern for human induced climate change), and individual action (i.e., a demonstrated unwillingness to compromise air travel behaviour). 'I think this issue is going to be more and more intense and that is why I, personally, am ready to change. In the meantime, I'm taking a sleeping pill... as if this is too abstract' (Johannes, 57).

\section{Tourism management implications}

This study found acceptance of human contributions to climate change and the mainstreaming of climate concern in Norway. This contrasts the dominant discourse (Becken, 2004; Gossling et al., 2007), including the 'psychology of denial' (Gössling $\&$ Peeters, 2007) identified by earlier studies, including Hares et al. (2010: 468), who note in the United Kingdom context that "many... were unsure about what climate change is and some were skeptical it was taking place". It also highlights a continuing 
reluctance to accept individual responsibility for a collective problem. Following Donnelly (2008), our study highlights the responsibility of greater 'carbon culprits' (such as non-renewable energy providers and coal-based heavy industries) to lead the process of meaningful change. It also highlights the sacrosanct status of air travel. We found that Norwegians, like other European markets such as the UK and Germany (Donnelly, 2008; Hares et al., 2010), consider long-haul travel to be relatively infrequent and, consequently, justifiable (in relative terms). Interestingly, the high climate change liability that interviewees felt concerning their frequent short-haul flights did not extend to long-haul air travel. Rather the view was expressed that other 'luxuries' would be willingly sacrificed to protect long-haul air travel.

These sentiments exist in association with confusion surrounding the climate change consequences of individual air travel. Confusion, it appears, is a significant barrier acting against personal climate change action. Modest changes that are economic to commit to, and of little personal inconvenience, describe the current domestic Norwegian response to climate concern. This confusion is also manifest in a current unwillingness to forego air travel opportunities or otherwise reduce air travel frequency. Rather participants identified strategies (e.g., multiple destination itineraries, extended length of stay) to relieve sentiments of guilt. However, it cannot be assumed that these mitigation measures will necessarily result in an overall reduction in the total $\mathrm{CO}_{2}$ emissions associated with visiting long-haul destinations.

Hares et al. (2010) refer to an 'information deficit' that suggests the need for awareness to be raised as a precursor to behavioural change, and we found some evidence to suggest that information on air travel and climate change may facilitate behavioural change. 'As of today, I would travel without having the environment as a major factor... Until I have enough information to say, okay, I cannot travel by air unless it's absolutely necessary anymore. I'm not at that stage right now' (Pål, 34). It is likely that, in association with a commitment to carbon neutrality, governments may seek to address this information deficit, but perhaps only when international air transport emissions become subject to liability under a post-Kyoto Protocol. Complicating matters, we also found evidence to the contrary that, in support of Randles and Mander (2009), suggests the social embeddedness of air travel practice. 'So it's cultural - the way of behaviour... We have started travelling and we would like to see more, and so on' (Silje, 45). This view prevailed to the extent that information campaigns alone appear unlikely to lead to air travel behaviour change in Norway.

These findings may be situated on a continuum of air travel carbon consciousness (Figure 1). Our study provides evidence of acceptance of climate change in Norway (albeit in the general absence of air travel behaviour change) and what we term 'air travel with a carbon conscience'. This stands in sharp contrast to Hares at al. (2010: 470), who report in their UK study climate change denial (Figure 1) and "... a strong reluctance across all groups to consider changing their tourism behaviour". In Norway, air travel is not divorced from climate change concerns. While manifest changes in travel behaviour may be slow, air travel is not considered to be set apart from 
individual climate concern liability, as is the reported case in the UK (Donnelly, 2008; Hares et al., 2010). A clear differentiation between frequent short-haul (high climate change liability) and infrequent long-haul air travel (which is generally considered to be exempt from liability) is noteworthy. However, our assessment of the emergence of 'air travel with a carbon conscience' highlights several tourism management points of relevance to extreme long-haul destinations.

\section{Insert Figure 1 here}

\subsection{Multiple purpose/ multiple destinations.}

Our study signals a move in the Norwegian extreme long-haul travel market towards longer duration, multiple purpose travel. 'Since you're putting so much money into the distance of the flights, you would really need to be there for longer; fewer visitors staying there for longer' (Frode, 37). Following Weaver and Lawton (2010) it appears that leisure-based tourism alone may in due course become insufficient to justify longhaul travel; leisure travel may be more likely if taken in association with other motives such as visiting friends or relatives, gaining work experience and/or education. This finding sits alongside the expressed view that travel to New Zealand should not take place independently from visiting other destinations as part of a combined itinerary.

While New Zealand is understandably a dedicated single destination for Australian visitors, dual or multiple destination visits are common among long-haul markets (Ministry of Tourism, 2009c). This is due in large part to the need for most to 'break the journey' (through stopovers in Asia or North America) when travelling from Europe to New Zealand. Most European travellers to New Zealand also visit Asia (Singapore, Bangkok, Hong Kong) or the USA. Australia (40\%) is the most common co-destination of non-Australian visitors to New Zealand (Ministry of Tourism, $2009 \mathrm{c})$. The current study suggests an increasing propensity in the future to undertake multiple destination long-haul travel itineraries. These findings may signal the need for different components of government and industry to work more closely together to facilitate longer duration and multiple purpose visits to New Zealand. It may also signal the need for different components of the industry to work more closely together (e.g., event management organisations, conference organisers, networks of attractions and airlines), and the industry as a whole to work more closely with other industry sectors, in transnational collaboration with Australia, South Pacific and other AsiaPacific destinations.

\subsection{Protect the $100 \%$ Pure New Zealand brand}

Growing climate concern in the Norwegian market would suggest the need for measures to ensure that New Zealand's branding efforts do indeed withstand close scrutiny (Becken, 2007). This would see New Zealand seek a position of eminence in terms of low energy, sustainable living (see Donnelly, 2008), both in domestic life, but also in terms of low energy accommodation, travel and visitor activities. 'If New Zealand is pushing on and showing that the companies and people in New Zealand are 
aware and take the issues seriously, in one way you would be more interested in going there... [to] be influenced in a positive way' (Pål, 34).

Protection of New Zealand's brand image requires high environmental performance in the tourism sector. This may include supporting and profiling certified low carbon operators in all sectors of the tourism industry (e.g., transport, accommodation, visitor activities) (Donnelly, 2008) and seeking to position New Zealand as an exemplary nature tourism destination. New Zealand's international brand image may also be linked to government policy on climate change, leadership in international governance, and national as well as international leadership on issues relating to nature conservation.

\subsection{Develop climate concern mitigation measures.}

While visiting New Zealand remains extraordinary, this privileged position can be protected in ways that alleviate sentiments of guilt associated with air travel. Our study supports the findings of Donnelly (2008) who reports in the Australian context the need to help visitors to relieve their carbon concerns. This might include increased clarity and transparency of New Zealand carbon offsetting schemes (so that visitors can actually see the environmental benefit of the offset they purchase) and carbon audits to ensure low energy visitor experiences. Slow travel initiatives and low carbon activities (Dickinson, Robbins \& Lumsdon, 2010), supported by initiatives such as the development of a national cycle way (National Business Review, 2009), may foster greater length of stay, which has emerged in this study as an important element of climate concern mitigation.

\section{Conclusion}

Our findings indicate that, relative to other European markets (e.g., UK, Germany), Norway may be considered a vanguard tourism market in terms of climate concern. We found little evidence of the 'psychology of denial' that pervades in the UK (Gössling \& Peeters, 2007; Hares et al., 2010). Rather, in Norway we found an acceptance of human-induced climate change and a willingness to make (mainly domestic) behavourial changes to address climate concerns. In Norway there is an apparent awareness of, and concern for, the contribution of air travel to climate change. This finding contrasts several recent studies of international tourists (Gössling et al., 2006; Becken, 2007) and is consistent with the recently published work of Gössling et al. (2009).

We also note, however, a continuing discrepancy between attitudes and behaviour. While we found little evidence of 'denial', concern for frequent air travel was accompanied by an unwillingness to forego long-haul air travel. Our study supports the findings of Becken (2007), Donnelly (2008) and Hares et al. (2010), who all found that regular air travel is considered too important to be curtailed by abstract and uncertain concerns about climate change. Like Randles and Mander (2009), we note that air travel has become deeply embedded in contemporary affluent western lifestyles, to the point of intransigence. Future research should continue to examine air 
travel attitudes and behaviours which, in addition to nationality, may also diverge on generational or other demographic grounds. Quantitative studies may build upon current qualitative insights (Hares et al., 2010; Cohen \& Higham, in press) to achieve results that can be generalised based on specific demographic variables including nationality.

However, we observe a growing conscience associated with long-haul air travel that coexists, perhaps somewhat uncomfortably, with continuing intentions to undertake extreme long-haul air travel to far-off destinations such as New Zealand. We have highlighted how this tension has begun to manifest through adapted behavioural intentions, including longer stays, the bundling of multiple destinations and a growing need for multiple motivations in order to justify the $\mathrm{CO}_{2}$ emissions associated with long-haul air travel. While an appetite for long-haul travel remains clearly evident, a growing air travel consciousness gives exclamation to the current position of New Zealand's Ministry of Tourism; that climate change poses a critical challenge to the tourism industry, and that monitoring and responsiveness to changing consumer attitudes towards air travel is paramount.

\section{References}

Agnew, M. \& Viner, D. (2001). Potential impact of climate change on international tourism. Tourism and Hospitality Research, 3, 37-60.

Becken, S. (2002). Analysing International Tourist Flows to Estimate Energy Use Associated with Air Travel. Journal of Sustainable Tourism, 10(2), 114-131.

Becken, S. (2004). How tourists and tourism experts perceive climate change and carbon-offsetting schemes. Journal of Sustainable Tourism, 12(4), 332-345.

Becken, S. (2007). Tourists' Perception of International Air Travel's Impact on the Global Climate and Potential Climate Change Policies. Journal of Sustainable Tourism, 15, 351-368.

Becken, S. \& Hay, J.E. (2007). Tourism and climate change: Risks and opportunities. Clevedon (UK): Channel View Publications.

Brand, C., \& Boardman, B. (2008). Taming of the few - the unequal distribution of greenhouse gas emissions from personal travel in the UK. Energy Policy, 36, 224-238.

Cohen, S. \& Higham, J.E.S. (in press). Eyes wide shut? UK consumer perceptions on aviation climate impacts and travel decisions to New Zealand. Current Issues in Tourism.

Denzin, N.K. \& Lincoln, Y.S. (2005). Introduction: The discipline and practice of qualitative research. In N.K. Denzin and Y.S. Lincoln (Eds). The Sage Handbook of Qualitative Research (Ed. 3). Thousand Oaks, CA: Sage Publications. pp 1-32.

Dickinson, J. E., Robbins, D. \& Lumsdon, L. (2010). Holiday travel discourses and climate change. Journal of Transport Geography, 18, 482-489.

Donnelly, D. (2008). Propensity for UK and German travelers to adapt travel intentions due to rising awareness of climate change issues. Department of 
Resources, Energy and Tourism. Retrieved from www.ret.gov.au (accessed 1 November, 2009).

de Freitas, C. (2005). The climate-tourism relationship and its relevance to climate change impact assessment. In C.M. Hall and J.E.S. Higham (Eds). Tourism, Recreation and Climate Change. Clevedon: Channel View Publications. pp. 2943.

Fontana, A. \& Frey, J.H. (2005). The Interview: From neutral stance to political involvement. In N.K. Denzin and Y.S. Lincoln (Eds). The Sage Handbook of Qualitative Research (Ed. 3). Thousand Oaks, CA: Sage Publications. pp 695728.

Gössling, S. (2002). Global environmental consequences of tourism. Global Environmental Change, 12(4), 283-302.

Gössling, S. (2009). Carbon neutral destinations: a conceptual analysis. Journal of Sustainable Tourism, 17(1), 17-37.

Gössling, S., Bredberg, M., Randow, A., Sandström, E. \& Svensson, P. (2006). Tourist perceptions of climate change: a study of international tourists in Zanzibar. Current Issues in Tourism, 9(4\&5), 419-435.

Gössling, S., Haglund, L., Kallgren, H., Revahl, M. \& Hultman, J. (2009). Swedish air travellers and voluntary carbon offsets: towards the co-creation of environmental value. Current Issues in Tourism, 12(1), 1-19.

Gössling, S. \& Hall, C. M. (2005). Wake up! This is serious. In Gössling, S. and Hall, C.M. (Eds). Tourism and Global Environmental Change. Ecological, social, economic and political interrelationships. London: Routledge, pp. 305-320.

Gössling, S., \& Hall, C. M. (2006). Uncertainties in predicting tourist flows under scenarios of climate change. Climatic Change, 79(3), 163-173.

Gössling, S., \& Hall, C. M. (2008). Swedish Tourism and Climate Change Mitigation: An Emerging Conflict? Scandinavian Journal of Hospitality and Tourism, 8(2), 141-158.

Gössling, S., \& Peeters, P. (2007). 'It Does Not Harm the Environment!' An Analysis of Industry Discourses on Tourism, Air Travel and the Environment. Journal of Sustainable Tourism, 15, 402-417.

Gössling, S., Peeters, P., \& Scott, D. (2008). Consequences of Climate Policy for International Tourist Arrivals in Developing Countries. Third World Quarterly, 29(5), 873-901.

Gössling, S., \& Upham, P. (Eds.). (2009). Climate change and aviation: Issues, challenges and solutions. London: Earthscan.

Hares, A., Dickinson, J. \& Wilkes, K. (2010). Climate change and the air travel decisions of UK tourists. Journal of Transport Geography, 18(3), 466-473.

Høyer, K., (2000). Sustainable tourism or sustainable mobility? The Norwegian case. Journal of Sustainable Tourism, 8(2), 147-160.

Lusseau, D. \& Higham, J.E.S. (2004). Managing the impacts of dolphin-based tourism through the definition of critical habitats: The case of bottlenose dolphins (Tursiops spp.) in Doubtful Sound, New Zealand. Tourism Management, 25(5),657-667.

Ministry of Tourism (New Zealand) (2009a). Tourism; Leading Indicators Monitor. July 2009. Retrieved from 
http://www.tourismresearch.govt.nz/Documents/TLIM/TLIM\%20Commentary \%202009/TLIMJuly2009Commentary.pdf (Accessed 30 October 2009).

Ministry of Tourism (New Zealand) (2009b). Climate change. Retrieved from http://www.tourism.govt.nz/Our-Work/Our-Work-Summary-page/Climate-Change/ (Accessed 30 October 2009).

Ministry of Tourism (New Zealand) (2009c). Tourism sector profile. Retrieved from http://www.tourismresearch.govt.nz/Documents/International\%20Market $\% 20 \mathrm{Pr}$ ofiles/Total\%20Profile.pdf (Accessed 30 October 2009).

Ministry of Tourism (New Zealand) (2010). International Visitor Arrivals (IVA) Key Data. Retrieved from: http://www.tourismresearch.govt.nz/Data-Analysis/International-tourism/International-Visitor-Arrivals/IVA-Key-Data/ (Accessed 14 March 2010).

Monbiot, G. (2007). Heat: How to stop the planet burning. London: Penguin Books. National Business Review (2009). Key turns sod on national cycleway project. Retrieved from http://www.nbr.co.nz (accessed 30 November, 2009).

OECD (2009). Economic Survey - Norway: Some aspects of sustainable development. Retrieved from http://www.oecd.org/documents.html (accessed 3 December, 2009).

O'Reilly, K. (2005). Ethnographic methods. London: Routledge.

Patton, M.Q. (2002). Qualitative research and evaluation methods. Thousand Oaks: Sage Publications.

Penner, J. E., Lister, D. H., Griggs, D. J., Dokken, D. J., \& McFarland, M. (1999). Aviation and the global atmosphere - a special report of IPCC working groups I and III (Intergovernmental panel on climate change). Cambridge: Cambridge University Press.

Randles, S., \& Mander, S. (2009). Practice(s) and ratchet(s): A sociological examination of frequent flying. In S. Gössling and P. Upham (Eds). Climate change and aviation: Issues, challenges and solutions. London: Earthscan. pp. 245-271.

Richardson, R.B. \& Loomis, J.B. (2005). Effects of climate change on tourism demand and benefits in alpine areas. In C.M. Hall and J.E.S. Higham (Eds). Tourism, Recreation and Climate Change. Clevedon: Channel View Publications. pp. 164-180.

Scott, D., Wall, G. \& McBoyle, G. (2005). The evolution of the climate change issue in the tourism sector. In C.M. Hall and J.E.S. Higham (Eds). Tourism, Recreation and Climate Change. Clevedon: Channel View Publications. pp. 4460 .

Shaw, S., \& Thomas, C. (2006). Discussion Note: Social and Cultural Dimensions of Air Travel Demand: Hyper-Mobility in the UK? Journal of Sustainable Tourism, 14(2), 209-215.

Smith, I. J., \& Rodger, C. J. (2009). Carbon offsets for aviation-generated emissions due to international travel to and from New Zealand. Energy Policy, 37(9), 3438-3447.

Statistics Norway (2010). Focus on Tourism. Retrieved from: http://www.ssb.no/reiseliv en/ (Accessed 14 March 2010)

United Nations World Tourism Organization (2008). Tourism Highlights 2008 
Edition. Retreived from

http://www.unwto.org/facts/eng/pdf/highlights/UNWTO_Highlights08_en_LR.p df (accessed 3 November 2009).

Wall, G. \& Badke, C. (1994) Tourism and climate change: an international perspective. Journal of Sustainable Tourism 2 (4), 193-203.

Weaver, D. \& Lawton, L (2010). Tourism Management (Ed. 4). Milton (Australia): Wiley.. 
Figure 1. Continuum of air travel carbon consciousness

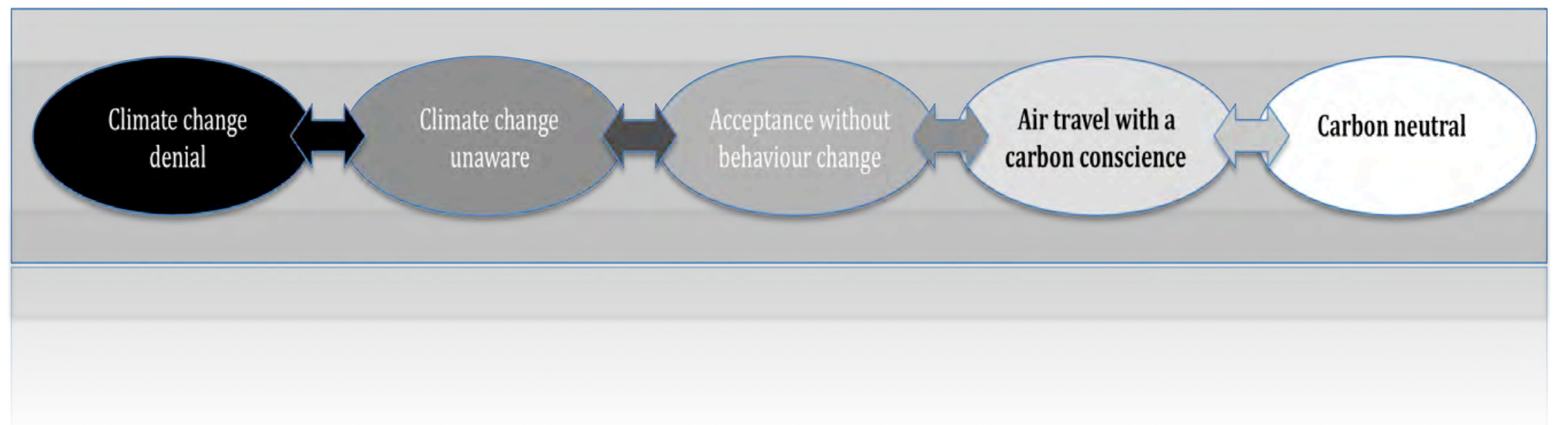


Table 1. Semi-structured schedule following three key interview themes.

\section{Theme 1: Climate change and domestic living decisions and behaviours}

a. Daily/household behaviours and decision making

b. Political allegiance

c. Public transport

d. Car (model) ownership, car pooling

e. Cycling

f. Choice of place of domestic residence

g. House design (e.g., Insulation/domestic heating)

Theme 2: Climate change and air travel decision-making (domestic and international)
a. Frequency of travel
b. Changes to travel patterns
c. Position on aviation industry
d. Activities at destination

\section{Theme 3: Climate change and attitudes towards long-haul air travel to New Zealand}

a. Concerns for climate impact of air travel

b. Potential changes in long-haul air travel behaviour

c. Factors of importance

i. Carbon offsetting

ii. Airline environmental performance

iii. Position on carbon neutral destinations

iv. Government position on climate change

v. Business performance at destination (e.g., energy efficiency)

vi. Activities at destination (e.g., slow tourism, low carbon activities) 
Table 2. Summary profile of interview programme participants.

\begin{tabular}{lccll}
\hline Pseudonym & Gender & Age & Occupation & Highest qualification \\
\hline Frode & M & 37 & Industry professional & Masters \\
Rita & $\mathrm{F}$ & 34 & Industry professional & Masters \\
Bjørn & $\mathrm{M}$ & 41 & Industry professional & PhD \\
Silje & $\mathrm{F}$ & 45 & Industry professional & Masters \\
Svein & $\mathrm{M}$ & 35 & Industry professional & High school \\
Tone & $\mathrm{F}$ & 58 & Postgraduate student & Masters \\
Ida & $\mathrm{F}$ & 52 & University administrator & Masters \\
Grete & $\mathrm{F}$ & 27 & Postgraduate student & Undergraduate \\
Lars & $\mathrm{M}$ & 53 & Academic & PhD \\
Pål & $\mathrm{M}$ & 34 & Industry professional & Masters \\
Hilda & $\mathrm{F}$ & 67 & Retiree & Masters \\
Håkon & $\mathrm{M}$ & 48 & Industry professional & Undergraduate \\
Johannes & $\mathrm{M}$ & 57 & Academic & PhD \\
Anette & $\mathrm{F}$ & 35 & University administrator & Masters \\
Grethe & $\mathrm{F}$ & 27 & Postgraduate student & Masters \\
\hline
\end{tabular}


Table 3. Summary of air travel frequency profile of interview participants

\begin{tabular}{|c|c|c|c|}
\hline Pseudonym & Type of air travel & Reason & Return flights per year \\
\hline \multirow[t]{4}{*}{ Frode } & Domestic short haul & Business & 24 \\
\hline & European short haul & Business & 1 \\
\hline & European short haul & Leisure & 1 \\
\hline & International medium/long haul & Business & $1 *$ \\
\hline \multirow[t]{3}{*}{ Rita } & Domestic short haul & Business & 2 \\
\hline & Domestic short haul & Leisure & 8 \\
\hline & European short haul & Leisure & 1 \\
\hline Bjørn & Domestic short haul & Business & 24 \\
\hline \multirow{4}{*}{ Silje } & Domestic short haul & Business & 22 \\
\hline & European short haul & Business & 2 \\
\hline & European short haul & Leisure & 1 \\
\hline & International medium/long haul & Leisure & 1 \\
\hline \multirow[t]{3}{*}{ Svein } & European short haul & Business & 2 \\
\hline & International medium/long haul & Business & 1 \\
\hline & European short haul & Leisure & $1 *$ \\
\hline \multirow[t]{2}{*}{ Tone } & European short haul & Business & 5 \\
\hline & European short haul & Leisure & 5 \\
\hline \multirow[t]{2}{*}{ Ida } & Domestic short haul & Leisure & 4 \\
\hline & International medium/long haul & Leisure & 1 \\
\hline \multirow[t]{2}{*}{ Grete } & Domestic short haul & Leisure & 4 \\
\hline & European short haul & Leisure & 2 \\
\hline Lars & European short haul & Business & 5 \\
\hline \multirow[t]{2}{*}{ Pål } & European short haul & Business & 1 \\
\hline & European short haul & Leisure & $1 *$ \\
\hline \multirow[t]{2}{*}{ Hilda } & International medium/long haul & Leisure & $1 *$ \\
\hline & International multiple long haul & Leisure & $1 *$ \\
\hline Håkon & European short haul & Leisure & $1 *$ \\
\hline \multirow[t]{3}{*}{ Johannes } & Domestic short haul & Business & 25 \\
\hline & European short haul & Leisure & 1 \\
\hline & International medium/long haul & Business & 2 \\
\hline Anette & European short haul & Leisure & $2 *$ \\
\hline Grethe & European short haul & Leisure & 1 \\
\hline
\end{tabular}

* Figures rounded up 